\title{
Frequency and the lexical storage of regularly inflected forms
}

\author{
JOSEPH PAUL STEMBERGER and BRIAN MACWHINNEY \\ Carnegie-Mellon University, Pittsburgh, Pennsylvania
}

It has often been hypothesized that speakers store regularly inflected forms as separate entries in the lexicon. If this hypothesis is true, high-frequency lexical items will have lower error rates on their inflections than will low-frequency lexical items. This is shown to be the case for errors on irregular inflected forms in naturally occurring speech errors. High-frequency regularly inflected forms exhibit a small (but nonsignificant) advantage in naturally occurring errors, and a larger (significant) advantage in a more controlled experimental task in which subjects produced the past-tense forms of regular verbs. These data are best explained by assuming that highfrequency inflected forms are stored as separate entries in the lexicon. Consequences of this finding for theories of language production and language learning are discussed.

Lexical items are a fundamental part of a speaker's knowledge of language. One of the major goals of psycholinguistics has been to determine how lexical items are accessed in perception and production, as well as how speakers learn lexical items. In this paper, we examine the ways in which speakers store regularly inflected forms such as dogs and talked. Our main focus will be on the use of these forms in production. There are two basic questions that we will ask regarding the representation of regularly inflected forms. First, are inflected forms such as walked stored in the lexicon? Second, do speakers analyze such forms into their component morphemes? For example, do speakers control words such as walked as a single psycholinguistic unit, walked, or as two units, walk and -ed? We can identify three main alternative positions based on different answers to these two questions. (1) Regularly inflected forms are controlled as two units and are not stored in the lexicon. (2) Regularly inflected forms are stored in the lexicon and are controlled as a single unit. (3) Regularly inflected forms are stored in the lexicon but are still controlled as two separate units. We will argue that the third alternative is true of at least highfrequency inflected forms. We will henceforth refer to the control of an inflected form as two units as "analysis" into two units, or morphemes.

Linguistic theory has been unable to arrive at a consensus regarding these three alternatives. Vennemann (1974) and Leben and Robinson (1977) argued that all

\footnotetext{
This research was supported in part by a Sloan postdoctoral fellowship to J. Stemberger, by NIH Training Grant NS-7134-06 to Indiana University, and by NICHHD Grant 1 R01 HDI7790 to B. MacWhinney. Revisions were made while the first author was a postdoc in Dave Pisoni's speech perception lab. We would like to thank Gary Dell, Paul Luce, Louisa Slowiaczek, and the anonymous reviewers for this journal for their helpful comments and criticisms of an earlier version of this paper. We thank Paul Luce for determining the similarity neighborhoods of the words used in Study 4 . Address reprint requests to J P. Stemberger. now at Department of Linguistics. University of Minnesota, Minneapolis, MN 55455
}

inflected forms were stored in unanalyzed form in the lexicon. They suggested that, since at least some highly irregular inflected forms were presumably stored in the lexicon as separate entries (e.g., went), it was plausible that all known inflected forms were so stored. Vennemann argued additionally that it was impossible to take any given surface variant of a word and derive all the other surface variants from it. Given sufficiently strict constraints on the phonological representations of lexical items, this argument entails that there must be separate storage for all inflected forms. Chomsky and Halle (1968) and Hudson (1980), making very different assumptions about constraints on phonological representations, assumed that all regularly inflected forms were analyzed and that none were stored in the lexicon. This position requires fewer lexical entries, minimizes the redundancy of lexical entries, and captures the recurrent similarities between different forms belonging to the same inflectional category. Researchers who support this position point to the productivity of regular inflections, noting that new inflected words are frequently added to the language without difficulty, which they take to imply that the inflectional pattern is encoded as a rule and stored permanently in the grammar. Jackendoff (1975) accepted the arguments for both storage and analysis and posited a model in which inflected forms were stored in the lexicon but were nonetheless analyzed into their component parts, so that a given form was represented as a sequence of two morphemes within its lexical entry.

There are no decisive linguistic data to differentiate between the three positions empirically, however. The strongest evidence for analysis, the productivity of regular patterns, is also compatible with storage without analysis; new forms can be created either by analogy (Paul, 1886) or by rules (usually referred to as "redundancy rules," but also occasionally as "schemas"). The use of such rules or of analogy would constitute a "fall-back procedure," applying only when the desired inflected form can- 
not be located in the lexicon (Butterworth, 1983; Bybee \& Slobin, 1982; Jackendoff, 1975; Leben \& Robinson, 1977).

Psycholinguistic studies have furthered our knowledge somewhat, but still cannot decide between the three positions (see Butterworth, 1983). There is evidence that irregular inflected forms are stored in the lexicon, but no evidence regarding regularly inflected forms. There is, however, evidence that regularly inflected forms are analyzed into two morphemes in language production (and possibly in perception).

There is no clear evidence that regularly inflected forms are stored in the lexicon in adult speech. MacWhinney (1978, 1982) and Peters (1983) argued for such storage in child language, noting that children often use a given inflected form accurately while still failing to use the inflected forms of most other words. Furthermore, children are more successful at producing the inflected forms of known words than they are at producing inflected forms of similar novel words, and less often inappropriately use the base form (Berko, 1958), implying that known forms are stored in the lexicon. However, it is unclear whether these stored chunks are maintained into adulthood. Kempley and Morton (1982), using a delayed recognition task, reported that priming a regularly inflected or base form with itself leads to more facilitation than does priming with any other regularly inflected form of the same word. They suggested that regularly inflected forms may be stored in the lexicon, but noted that an adequate model of episodic memory may be able to account for this fact without such storage.

Studies of adult language perceptual processing are equivocal regarding analysis of regularly inflected forms. Murrell and Morton (1974), Stanners, Neiser, Hernon, and Hall (1979), and Kempley and Morton (1982) have shown that regularly inflected forms facilitate their base forms (in terms of later recognition or of response latency in a lexical decision task) and other regularly inflected forms of the same base word much more than irregularly inflected forms facilitate their bases. Such data support the view that irregularly inflected forms are stored separately from their base forms in the lexicon. These researchers have also argued that the results require the analysis of regularly inflected forms into their component parts, with the morpheme being the basic unit of recognition. However, Bradley (1980) and Lukatela, Gligorijevic, Kostic, and Turvey (1980) have suggested that these data are compatible with the separate storage of regularly inflected forms without analysis, provided that the separate entries of the regularly inflected forms of a given word can be clustered together while the separate entries of irregular inflected forms are fully independent. Taft (1984), using a task in which subjects had to determine whether a given word had a homophone that was spelled differently, found that subjects were more accurate if the two words had the same morphological structure (knead and need, or heeled and healed) than if only one was inflected (fined and find, or lax and lacks). He argued that sub- jects were stripping off the affix and searching for homophonous base forms, leading to poorer performance on mixed trials. However, it appears that the results may be due to greater orthographic differences found in the mixed conditions than in the other conditions. Gibson and Guinet (1971) found that inflections were more accurately perceived at short visual presentations than were phonologically matched noninflectional phonemes, implying that inflections were processed separately from base forms. However, it is possible that analogical effects in interactive activation models might be able to account for these data without any analysis into morphemes (see Stemberger, 1985b).

Evidence for the analysis of regularly inflected forms is clearer in language production. Walsh and Parker (1983), using minimal pairs such as wrecks and Rex, reported that the plural morpheme $-s$ is about 9 msec longer than an /s/ that is a part of the base form, suggesting that $-s$ is a separate morpheme. Stemberger (1984) found that speakers make fewer mispronunciation errors on inflections in natural speech than they do on phonologically matched noninflectional phonemes, implying that inflections are separate from base forms (although, again, this could be attributed to analogical effects in interactive activation models, with no analysis). Errors that occur in spontaneous speech provide three other arguments for the analysis of regularly inflected forms. First, affix shifts, in which a regular inflection erroneously appears on a word earlier or later in the sentence as in tell-us-ing for "telling us," are common, whereas shifts involving nonmorphemic material at the ends of words are rare (Garrett, 1980; Stemberger, 1985b). The characteristics of these affix shifts are identical to those of the shifts of independent closed-class lexical items such as prepositions, articles, and particles (Stemberger, 1985b). Second, a phonological error at the end of a word usually leads to a change in the pronunciation of an inflection to make it appropriate to the new phonological environment, a phenomenon known as "morphological accommodation" (Garrett, 1980; Stemberger, 1985b). For example, the loss of the stem-final $/ \mathrm{t} /$ in grapefruits (/fru:ts/) led to the error grapefrues (/fru:z/, with the voiced variant of $-s$ that is appropriate after $/ \mathrm{u}: /$ ) rather than *grapefrooss (/fru:s/), with the voiceless variant of $-s$ that appears in the correct form of the word. This implies analysis into morphemes and a rule governing the distribution of the variants of the inflection. Third, the relative frequencies of three types of errors on irregular forms (with full regularizations such as choosed and base-form errors such as sing being common, and partial regularizations such as tooked being uncommon) also require that there be a rule for past/perfect -ed. Stemberger (1985b) argued that this rule must be an integral part of inflectional processing rather than a fall-back procedure, implying that at least some regularly inflected forms are created by rule and not stored in the lexicon.

Stemberger and MacWhinney (in press) examined inflectional errors in an experimental task in which subjects 
were asked to produce a given inflected form of a presented verb. They found that speakers often failed to add an inflection to a base form that resembled an irregularly inflected form (e.g., spank), but only if the base form rhymed with several irregularly inflected forms, implicating analogy to irregular forms. They found that speakers also often failed to add an inflection to a base that ended with a phoneme that resembled the inflection (e.g., kiss with $-s$, need with -ed), but that it made no difference whether the base form rhymed with occurring regularly inflected forms. An effect of rhyming would have been expected if all regularly inflected forms were stored in the lexicon. Stemberger and MacWhinney argued that present $-s$ and past -ed must be added via a rule for at least some inflected forms even for familiar words.

On the basis of current data, then, we can say that there is good psycholinguistic evidence that regularly inflected forms are analyzed into their component morphemes and that irregularly inflected forms are stored in the lexicon. However, there is no adult psycholinguistic data indicating that regularly inflected forms are stored in the lexicon. It is the purpose of this paper to examine whether any regularly inflected forms are separately stored in the lexicon and, if so, whether they are analyzed into their constituent morphemes.

The separate storage of regularly inflected forms predicts the existence of frequency effects based specifically on the frequency of the inflected form. It is well known that high-frequency items are characteristically less subject to error than are low-frequency items (Atkinson \& Shiffrin, 1968; Ebbinghaus, 1885/1913; Estes, 1955; MacKay, 1982; McClelland \& Rumelhart, 1981; Shiffrin \& Schneider, 1977; Thorndike, 1898). If the speaker constructs separate lexical representations for individual regularly inflected forms, there should be a lower rate of all types of errors on high-frequency inflected forms than on low-frequency inflected forms, especially with "nomarking" errors, in which the speaker successfully accesses the base form of the word but fails to access the inflection, saying, for example, walk when walked is intended. No such frequency prediction is made if regularly inflected forms are not separately stored in the lexicon. Without separate storage, the rate of no-marking errors would be related only to the frequency of the inflection itself, with high-frequency inflections showing a lower error rate than low-frequency inflections (a prediction that is true of aphasia and at least partly true of normal speech; see Stemberger, 1985a). However, there is no reason to expect that success or failure on accessing the inflection would be affected by the frequency of the base form or of the inflected form itself. With a given inflectional affix, we should find no effect of the frequency of the inflected form or of the base word. (We will argue against this in more detail below.) These contrasting predictions provide us with a way of obtaining direct evidence on this issue: the presence of an effect of the frequency of individual inflected forms would implicate separate storage of inflected forms, whereas the lack of a frequency effect would implicate analysis without storage.
The resistance of high-frequency forms to errors has been demonstrated in language processing in a number of ways, both directly and indirectly. Hooper (1976) and Bybee and Brewer (1981) found that high-frequency irregularly inflected forms survived longer in the history of a language without being regularized out of existence. In free recall (e.g., Hall, 1954), high-frequency words are much easier to recall. Ellis, Miller, and Sin (1983) showed that jargon aphasics were more likely to produce jargon when they were required to produce a lowfrequency word than when they were required to produce a high-frequency word. Howes (1964) showed that aphasics did not use low-frequency lexical items, suggesting that they found them much harder to access. Stemberger (1984) showed that low-frequency open-class lexical items were more susceptible to lexical accessing errors than were high-frequency open-class lexical items. These lines of evidence suggest that high-frequency forms are easier to produce. However, the specific hypothesis that high frequency protects a word from errors on its constituent phonemes and morphemes has never been demonstrated for the errors of normal adult speakers of a language. Study 1 tested for this frequency effect in phonological speech errors from spontaneous speech to allow us to determine whether the theoretically derived frequency predictions about inflected forms made above were plausible.

\section{STUDY 1:}

\section{Frequency and the Rate of Phonological Errors}

\section{Method}

The speech errors analyzed here are from a corpus of 7,200 errors that the first author has collected from natural speech situations over a period of 5 years. These data are observational in nature and were collected with standard collection procedures. The author monitored speech for errors, and wrote down all the errors that were detected and as much contextual information as possible. The speakers who made the errors were all normal adult native speakers of English who showed no signs of language abnormalities. Errors were collected only in situations in which enough attention could be spared to the task to give it some degree of accuracy; this was effected as a (partial) control for perceptual biases, which may be intensified under conditions in which the listener does not devote much attention to detecting errors. Phonological errors (i.e., mispronunciations) were identified; only open-class lexical items will be considered here, since closed-class items vary greatly in some characteristics, such as stress, which have been shown to affect the detectability of errors and phonemes in general (Cole \& Jakimik, 1980; Cutler, 1980). Phonological errors of all types and all degrees of complexity were included. Examples are presented in (1) through (6).

1. You can just TORN north. "turn",

2. I couldn't even find the HICE key. "house"

3. I LIKES to FICK cold peas with onions. "like ... fix"

4. Oh, we PANT peas every spring. "plant"

5. Do you think it"s a plain-clothes CLOP? "cop"

6. I thought I heard a THOLLOW HUD. "hollow thud"

In phonological errors involving two words, such as the reversal of word-initial phonemes in (6) or the shift of the /s/ from one word to the other in (3), each word was treated as a separate error for the purposes of the present analysis. 
To analyze these errors in terms of word frequency, it was first necessary to determine the frequency distributions of correctly used words. The word frequencies were taken from Francis and Kucera (1982). The frequencies given there were derived by summing over all the inflected forms of a word. For example, the frequency of walk is the sum of the frequencies of walk, walks, walking, walked, and walked. Inspecting the entries of all words, it was determined that the midpoint for the distribution of open-class lexical items was 84 occurrences per million words; half the tokens belonged to words above this point, and half belonged to those below. A high-frequency group was created with all words that had a frequency of 85 or greater, and a low-frequency group was created with all words that had a frequency of 84 or less. Note that the low-frequency group contained many words that were still of quite high frequency in relation to very low-frequency words. If words with a frequency of, say, 75 were as effective at lowering error rates as words that were placed in the high-frequency group here, it would have the effect of lowering the error rate on words in the low-frequency group. This could only make any differences between the two groups harder to detect, and could in no way contribute to significant differences between the groups. To demonstrate an effect of lexical frequency on phonological errors, we deemed it sufficient to divide the lexicon in the way we have described.

The frequency of each word involved in the 3,372 phonological errors in the corpus was determined, and the errors on highfrequency versus low-frequency words were totaled. In the examples above, (1), (2), and (3) involve high-frequency words (turn, house, like, and fix); those in (4), (5), and (6) involve low-frequency words (plant, cop, hollow, and thud). A rough numerical approximation of error rates was computed for the high- versus lowfrequency groups by dividing the number of errors in each group by the combined frequency of the words in each group. This approximation assumes that all the errors in the corpus were drawn from a sample of one million words. The actual sample size is, of course, unknown, but the approximation is useful for showing the relative error rates in each condition.

\section{Results and Discussion}

The number of phonological errors on high- and lowfrequency words is given in Table 1 along with the frequencies for each group derived from Francis and Kučera (1982) and the relative error rate. There are far more errors on low-frequency words than on high-frequency words; $62.5 \%$ of the errors occur on low-frequency forms, and chance is only $50.1 \%$. This difference is highly significant $\left[\chi^{2}(1)=207.03, p<.0005\right]$. High frequency appears to make a word less susceptible to errors on its parts, such as phonological errors.

These findings indicate that one of the consequences of high frequency is greater accuracy and a lower error rate on the parts of the word, as many theories of cognitive functioning would predict. Thus, if inflected forms are separately stored in the lexicon, we would expect that the rate of no-marking errors on inflected forms would be affected by the frequency of the inflected form. This effect should hold for both regularly and irregularly in-

Table 1

Phonological Errors on High- Versus Low-Frequency Words in Spontaneous Speech

\begin{tabular}{cccc}
\hline $\begin{array}{c}\text { Individual } \\
\text { Frequency }\end{array}$ & $\begin{array}{c}\text { Group } \\
\text { Frequency }\end{array}$ & $\begin{array}{c}\text { Number of } \\
\text { Errors }\end{array}$ & Rate \\
\hline Low & 241,818 & 2,107 & .0087 \\
High & 241,325 & 1,265 & .0052 \\
\hline
\end{tabular}

flected forms. Since it is generally agreed that separate lexical storage is most likely for irregularly inflected forms, we first checked to see if the predicted frequency effects were true for these forms. We wished then to determine whether the predictions would also be borne out for regularly inflected forms. Later, we tested these predictions using an experimental task to induce errors in the production of regular past-tense forms.

\section{STUDY 2:}

\section{Irregular Verbs in Spontaneous Speech Errors}

\section{Method}

The corpus of spontaneous speech errors was the same as that used in Study 1. No-marking errors on the past-tense forms and perfect-aspect forms of all irregular verbs (except the auxiliaries was, were, did, and had) were identified and tallied; in all cases, the linguistic and extralinguistic context clearly required the verb to be in the past or perfect form, but it was produced with the simple base form of the verb instead. Examples of the errors are presented in (7) through (11).

7. Boy, that DRAW him out --- drew him out.

8. He had WIND up making $\$ 200$. "wound"

9. A while ago, I FIND a --- I found a white hair.

10. What was it you just SING? "sang"

11. When Joe's GO, I occasionally put on... "gone"

Frequency values per million words of printed text for each of the irregular past and perfect forms of English were derived from Francis and Kucera (1982). The verbs were then divided into a highfrequency and a low-frequency group. The high-frequency group contained all forms with a frequency of 35 per million or greater; the low-frequency group contained all forms with a frequency less than 35 . Note that the cutoff point between high- and low-frequency forms was much lower than in Study 1. This reflected the fact that the frequency of a given inflected form was much lower than the frequency of the word as a whole, summing over all inflected and base forms. A frequency of 35 was chosen because it was close to the midpoint of the frequency distribution of all inflected forms. Upon examination of any given inflection, it can be seen that the high- and low-frequency groups differ in group frequency. However, a single cutoff was used for all inflected forms in order to ensure uniform treatment between studies. The number of tokens of all irregular forms in each group was summed, yielding a group frequency of high- versus low-frequency past and perfect irregular forms in English that constitutes an estimate of chance. The raw numbers of errors in each group were divided by the group frequency to yield an approximation of the error rate, under the assumption that the errors were sampled from a corpus of one million words. Since the actual sample size is unknown, these rates are best used to reflect the relative error rates on different groups of verbs.

\section{Results and Discussion}

The number of no-marking errors is shown in Table 2, along with the group frequencies of the low- and highfrequency irregular past and perfect verb forms and the relative error rate for each group. There is a much greater error rate on low-frequency inflected forms than on highfrequency inflected forms; $30.4 \%$ of the errors occur on low-frequency forms; chance is only $10.4 \%$. This difference is highly significant $\left[\chi^{2}(1)=23.90, p<.0005\right]$.

The prediction made above, that high frequency should lead to fewer errors, is supported by these data from ir- 
Table 2

No-Marking Errors on High- Versus Low-Frequency Irregular Past and Perfect Forms in Spontaneous Speech

\begin{tabular}{cccc}
\hline $\begin{array}{c}\text { Individual } \\
\text { Frequency }\end{array}$ & $\begin{array}{c}\text { Group } \\
\text { Frequency }\end{array}$ & $\begin{array}{c}\text { Number of } \\
\text { Errors }\end{array}$ & Rate \\
\hline Low & 1,735 & 17 & .0098 \\
High & 15,012 & 39 & .0026 \\
\hline
\end{tabular}

regular verbs. As noted above, previous research had provided several types of evidence supporting separate storage for such irregular forms. We now turn to the more uncertain issue of whether regularly inflected forms are also stored separately in the lexicon. If they are, then highfrequency regularly inflected forms should be less susceptible to error than low-frequency regularly inflected forms. Study 3 was designed to test this hypothesis.

\section{STUDY 3:}

\section{Regular Verbs in Spontaneous Speech Errors}

\section{Method}

The corpus of spontaneous speech errors used was the same as that described above. No-marking errors on regular past and perfect verb forms, such as need, interpret, and harvest, were identified, using both the linguistic and extralinguistic context to determine that the -ed suffix should have been present but was not. Group frequencies for the high-frequency verb forms (frequency of 35 or greater on the inflected form) and the low-frequency verb forms (frequency less than 35 ) were determined by summing the individual frequencies of all these verb forms in Francis and Kucera (1982), as in Study 2. Relative error rates were computed as in Study 2.

\section{Results and Discussion}

The number of no-marking errors is shown in Table 3, along with the group frequencies of the high- and lowfrequency regularly inflected past and perfect verb forms and the relative error rates for both groups. There are more errors involving low-frequency inflected forms than there are involving high-frequency inflected forms. However, this difference is not significant $\left[\chi^{2}(1)=2.03\right.$, $p>.10]$.

Although the observed differences between high- and low-frequency regularly inflected forms were not significant, it should be noted that they were in the predicted direction. This suggests that high-frequency inflected forms may be separately stored in the lexicon. Like irregularly inflected forms, this separate storage leads to a lower error rate. However, we cannot be certain of this, since the differences were not significant. It is clear that this effect is far weaker for regular forms than for irregular forms. The weaker effect with regularly inflected forms might be attributed to a floor effect. Speakers apparently find the production of regularly inflected past and perfect forms to be much easier than the production of irregular forms, as evidenced by the relative error rates presented in Tables 2 and 3 above. Low-frequency regularly inflected forms do have a higher error rate than highfrequency regularly inflected forms, but it is still signifi- cantly lower than the error rate on the high-frequency irregular forms $\left[\chi^{2}(1)=10.97, p<.001\right]$.

We can point to two reasons why regularly inflected forms might be easier than irregular forms. First, regularly inflected forms are far more common, in both type and token frequency. The regular -ed pattern is thus of higher frequency and so should be less susceptible to error. Second, only irregular verbs show a phoneme-based mismatch between the base and inflected forms, containing a vowel different from that of the base. There may be a tendency for the base vowel, rather than the vowel of the inflected form, to be accessed. This is expected, because errors often occur where the vowel and stress patterns of derivationally related words such as economics and economist occur on the wrong form, for example, ecoNOMist rather than $e$ CONomist under the influence of ecoNOMics (Cutler, 1980). Conflict between the vowel patterns of the base and irregular past tense form should be even greater, because they are more closely related semantically. With regularly inflected forms, in contrast, there is no mismatch between the base and inflected forms; with the exception of material that follows the base, they are identical.

Given these forces working against the strength of the frequency effect, it may be that the data base of nomarking errors that we have from spontaneous speech is simply too small to reliably detect the predicted frequency effect. For a stronger test of whether such an effect does indeed exist, we must turn to an experimental task in which no-marking errors can be gathered more easily. MacKay (1976), Bybee and Slobin (1982), and Stemberger and MacWhinney (in press) used such a task. They found that the rate of no-marking errors differed considerably on verbs with different characteristics. For Study 4, we selected a group of verbs that consistently showed a high error rate in the past tense-regular verbs that end in $/ t /$ or $/ d /$.

\section{STUDY 4:}

\section{Regular Past Tense}

\section{Method}

Subjects. The subjects were 75 members of the Carnegie-Mellon University subject pool, who received either credit in an introductory psychology course or money for their participation in the experiment.

Materials. A list of 40 English verbs was constructed, divided into 10 high-frequency verbs, 10 low-frequency verbs, and 20 distractors. The high-frequency group was made up of the 10 monosyllabic verbs that end in $/ t /$ or $/ d$ / with the highest frequency pasttense forms in English, according to Francis and Kucera (1982)

\section{Table 3}

No-Marking Errors on High- Versus Low-Frequency Regular Past and Perfect Forms in Spontaneous Speech

\begin{tabular}{cccc}
\hline $\begin{array}{c}\text { Individual } \\
\text { Frequency }\end{array}$ & $\begin{array}{c}\text { Group } \\
\text { Frequency }\end{array}$ & $\begin{array}{c}\text { Number of } \\
\text { Errors }\end{array}$ & Rate \\
\hline Low & 21,305 & 24 & .0011 \\
High & 16,315 & 11 & .0007 \\
\hline
\end{tabular}


add, end, need, nod, point, shout, sound, start, wait, and want The past-tense forms of these verbs had an average frequency of 75.4; the lowest past-tense form had a frequency of 29 . (Counting all forms of these verbs, the average frequency was 248.8 , with 62 being the lowest frequency. Note that the frequency of inflected forms seems to be correlated with the overall frequency of the word, and is generally high for high-frequency words and low for lowfrequency words.) The low-frequency group was made up of 10 low-frequency monosyllabic verbs that ended in $/ \mathrm{t} /$ or $/ \mathrm{d} /:$ band, boost, kid, mend, pout, raid, rot, sift, swat, and weed. The pasttense forms of these verbs had an average frequency of 0.5 , with 2 being the highest frequency. (Counting all forms of these verbs, the average frequency was 4.6 , with 11 being the highest.) Unlike the naturalistic data of Studies 2 and 3, the inflected forms used here do not form a continuum. We wanted to contrast past-tense forms of the highest frequency feasible (although we were forced to go below the cutoff of a frequency of 35 used in Studies 2 and 3 in order to obtain enough verbs) with very low-frequency pasttense forms.

Procedure. The verbs were presented one at a time in the frame "WAS _ING" in the center of the CRT display screen of an IBM personal computer. This frame was included to ensure that the subject perceived the presented word as a verb, since related nouns often existed. The subject read the verb silently, then spoke the past-tense form of the verb out loud into a microphone connected to a voice key. Instructions emphasized the need to react as quickly as possible. At the onset of the verbal response, the computer removed the verb from the display screen and presented the next verb $1.5 \mathrm{sec}$ later. All responses were recorded for later analysis. Each subject was first given 12 practice trials. The 40 experimental verbs were randomized differently for each subject.

\section{Results}

The no-marking errors elicited in the high- and lowfrequency groups are presented in Table 4 . There were 28 errors on the low-frequency group, but only 13 errors on the high-frequency group. This difference is significant when using an analysis of variance over the total number of errors in each condition by each subject $[F(1,74)=$ $4.44, p<.05]$; it does not reach significance in an analysis by item $[F(1,18)=2.26, p>.10]$. The results are also significant when using a Wilcoxon signed ranks test (two-tailed) over subjects $(19+, 10-, p<.05)$. It appears that high-frequency inflected forms are less susceptible to no-marking errors.

\section{Discussion}

These findings suppport the hypothesis that regularly inflected forms are stored separately in the lexicon. As

Table 4

No-Marking Errors in Study 4

\begin{tabular}{lrlr}
\hline \multicolumn{2}{l}{ High Frequency } & \multicolumn{2}{l}{ Low Frequency } \\
\hline end & 1 & band & 4 \\
need & 2 & boost & 2 \\
shout & 3 & kid & 7 \\
sound & 3 & mend & 2 \\
wait & 4 & raid & 1 \\
& & rot & 2 \\
& & swat & 8 \\
& & weed & 2 \\
Total & 13 & & 28 \\
\hline
\end{tabular}

noted above, separate storage predicts that high-frequency regularly inflected forms will have a lower rate of error on their parts than will low-frequency regularly inflected forms. In Study 1, we showed that high-frequency lexical items have a lower rate of phonological errors. In Study 4 , we showed that high-frequency regularly inflected forms have a lower rate of one type of inflectional error, the no-marking error. There appear to be three possible accounts for these findings.

First, the results of Study 4 are compatible with the view that all regularly inflected forms that are known to the speaker are stored separately in the lexicon. If this is the case, then all forms must be analyzed into their constituent morphemes, given the evidence reviewed above that regularly inflected forms are so analyzed.

Alternatively, one might wish to argue that speakers simply commit more resources to the base form, and that the inflection is occasionally left off when there are no resources left for the inflection. Any factor that would reduce the amount of resources needed to access the base form would increase the amount of resources available for accessing the inflection, reducing the rate of accessing failures for the inflection. Assuming that highfrequency lexical items require fewer resources, one predicts fewer no-marking errors with high-frequency base forms than with low-frequency base forms. There is a strong correlation between the frequency of the base form and the frequency of the past-tense form, so that the verbs in our high-frequency group have highfrequency bases, and those in the low-frequency group have low-frequency bases. This assumption about the allocation of resources thus predicts the results of Study 4 . However, this allocation of resources does not seem to be true of normal speech. If resources are allocated to affixes only after the base word has been accessed, and if there are insufficient resources to access the base form, no resources will be left to access the inflection. This predicts more lexical and phonological errors on inflections than on base forms. However, there are, in fact, fewer errors on inflections, both in normal speech (Garrett, 1980; Stemberger, 1984, 1985b) and in jargon aphasia (Butterworth, 1979). In addition, accessing failures that lead to the wrong base word or extreme phonological errors on the base word generally are accompanied by accurate access of the inflection in normal speech (Garrett, 1980; Stemberger, 1984, 1985b) and in jargon aphasia (Butterworth, 1979). Even if we were to assume that base and inflection are accessed in parallel but nonetheless draw on the same limited resources, we would expect that extreme cases of accessing failure, as often observed in jargon aphasia, would affect both the base and the inflection, and this is not the case. Since this allocationof-resources account makes wrong predictions about natural speech, it is not clear how it can be used to account for our data here. No current model of speech production or perception makes use of the concept of resource allocation. If the present data serve to stimulate 
thought along these lines, in an effort to escape from believing in the storage of regularly inflected forms, they will have served an additional useful function.

There is a third alternative that is more compatible with the data presented so far. According to this account, highfrequency and low-frequency inflected forms are treated in a quite distinct fashion. The greater accuracy observed on high-frequency regularly inflected forms in Studies 3 and 4 does not require that all regularly inflected forms be stored separately in the lexicon. The same results are predicted if high-frequency regularly inflected forms are separately stored, whereas low-frequency forms are not stored but are produced via an inflectional rule. Several researchers (Butler Platt, \& MacWhinney, 1983; Bybee \& Brewer, 1981; MacWhinney, 1978, 1982; Stemberger, $1985 \mathrm{~b}$ ) have, in fact, suggested that this would be a plausible state of affairs, although they cite no data that would require it. It might then be possible for the high-frequency regularly inflected forms that are separately stored in the lexicon to be unanalyzed, stored as a single unit rather than as a sequence of two morphemes (MacWhinney, $1978,1982)$. None of the evidence reviewed above for the analysis of regularly inflected forms into their component morphemes has specifically addressed this frequency-related issue.

We performed one more analysis of spontaneous speech error data to test this third alternative. We reexamined Stemberger's (1985b) data to determine whether affix shifts and morphological accommodation to phonological errors occurred on high-frequency inflected forms as well as on low-frequency forms. If they did, it would suggest that high-frequency regularly inflected forms are analyzed into their component morphemes. If they did not, it would be probable that they are not analyzed. Note that we were examining only whether the arguments for analysis were true of high-frequency regularly inflected forms. We needed to make no prediction about the relative rates of these two types of errors on high-versus low-frequency regularly inflected forms.

\section{STUDY 5:}

\section{Affix Shifts and Morphological Accommodation}

\section{Method}

The corpus of spontaneous speech errors was the same as that used in Study 1. Affix shift errors, such as tell-us-ing for "telling us" and let going for "letting go," and instances of morphological accommodation to phonological errors, such as grapefrues for "'grapefruits," tucks for "touches," and asted for "asked"' were identified and tabulated. The errors were divided into a highfrequency group (frequency of 35 or greater) and a low-frequency group (frequency less than 35 ).

\section{Results and Discussion}

The number of affix shifts and accommodations to phonological errors in high- and low-frequency regularly inflected forms is shown in Table 5. Affix shifts occur often with high-frequency inflected forms. In fact, highfrequency forms are overrepresented in affix shifts $(58.5 \%$ of errors vs. $45.9 \%$ of regularly inflected forms), although
Table 5

Affix Shift Errors and Morphological Accommodation to Phonological Errors as a Function of the Frequency of the Inflected Form

\begin{tabular}{cccc}
$\begin{array}{c}\text { Individual } \\
\text { Frequency }\end{array}$ & $\begin{array}{c}\text { Group } \\
\text { Frequency }\end{array}$ & Affix Shifts & Accommodation \\
\cline { 1 - 2 } Low & 66,871 & 17 & 11 \\
High & 56,801 & 24 & 3 \\
\hline
\end{tabular}

this does not reach significance $\left[\chi^{2}(1)=2.62, p<.20\right]$. Morphological accommodation to phonological errors also occurs with high-frequency forms. High-frequency forms are underrepresented in this type of error $(21.4 \%$ of errors vs. $45.9 \%$ of regularly inflected forms), although this just misses significance $\left[\chi^{2}(1)=3.38, p<.10\right]$, reflecting the lower rate of phonological errors on highfrequency forms found in Study 1. If high-frequency forms are stored as unanalyzed wholes while lowfrequency forms are analyzed into their component morphemes, most errors that fail to show morphological accommodation to phonological errors should occur on highfrequency forms. This is not true, however; both failures in the corpus involve low-frequency forms: /impout $\partial \mathrm{z} /$ for "imposes" and /noik a $\mathrm{z} /$ for "noises."

Affix shifts and morphological accommodation to phonological errors can involve high-frequency regularly inflected forms, at rates that do not reliably differ from those of low-frequency regularly inflected forms. Both types of errors provide good evidence that inflected forms are analyzed into their component morphemes. It thus appears that high-frequency regularly inflected forms are both stored in the lexicon and analyzed into their component morphemes, as suggested by Jackendoff (1975), Kempley and Morton (1982), and Stemberger (1985b). The data also allow us to conclude that low-frequency regularly inflected forms are analyzed into their component morphemes, but give us no evidence of whether they are stored separately in the lexicon or are, rather produced only via inflectional rules.

\section{GENERAL DISCUSSION AND CONCLUSIONS}

It appears that high-frequency inflected forms are less susceptible to at least one type of inflectional error-the no-marking error. The fact that high-frequency irregular past and perfect forms (Study 2) resist such errors is not too surprising, since it is clear from other data that these forms must be stored in the lexicon. What is more important here is the evidence that even regularly inflected high-frequency forms are stored in the lexicon. At the same time, we have provided evidence indicating that high-frequency regularly inflected forms are given analysis in the lexicon. Thus, inflected forms can be both analyzed into their constituent morphemes and stored in the lexicon in some fashion, as suggested by Jackendoff (1975), Kempley and Morton (1982), and Stemberger (1985b). These results agree with those of Taft and Forster (1975) and Taft (1981) for another type of lexical item. Taft and Forster have shown that prefixed words, such as rejuvenate, are analyzed into two morphemes(re- 
and juvenate) in word recognition, although they must be stored as a single lexical item because there is no separate word *juvenate. Our results lead to the same conclusion for a set of words that are in a different morphological domain (inflectional rather than derivational) and that, most importantly, are regular in form and meaning.

Our findings, especially in Study 1, highly constrain the way in which lexical frequency can be encoded in language production. First, lexical frequency must be encoded in such a way as to affect not only the access of the lexical item itself, but also the access of the parts of the lexical item. Second, frequency must be at least partially encoded in terms of "strength" (e.g., degree of activation). Miller and Ellis (in press) have pointed out that some current models of language processing do not encode lexical frequency in a way that is compatible with these two requirements. However, the models can be modified to do so. Interactive activation models of production (Stemberger, 1984, 1985b) encode frequency in the required fashion. High-frequency items have higher activation levels and pass more activation to their component phonemes and morphemes than do low-frequency items. Higher activation levels protect an item from error. As a result, high-frequency lexical items show a lower rate of phonological and inflectional errors than do lowfrequency lexical items. Morton's (1969) logogen model, in contrast, encodes lexical frequency in terms of a threshold, so that high-frequency words require less activation to be accessed than do low-frequency words. It is assumed, however, that all lexical items, once accessed, pass on identical amounts of activation to other levels in the system. In order to be extended from perception to production, this model must be modified so that highfrequency forms pass on more activation to their phonemes and component morphemes.

The model of Garrett (1980) and Shattuck-Hufnagel (1979) has never explicitly accounted for lexical frequency effects. It assumes a two-level system in which the phonological representation of a lexical item is first accessed and then copied out into an interim memory buffer, with phonological errors occurring during copying. Encoding lexical frequency purely in terms of order of search through a memory store, as in Forster's (1976) model, can account for the shorter reaction times in naming (Balota \& Chumbley, 1985) and the lower rate of lexical errors associated with high-frequency lexical items (including the results of Studies 2-4 above), but not for the lower rate of phonological errors (Study 1). Since accessing the phonological representation and copying it are fully independent processes, there is no way that an increase in lexical accessing time could affect the rate of phonological errors. The model must be modified so that the phonological representations of high-frequency and lowfrequency lexical items differ in a way that can affect the copying process. Brown and McNeill (1966) suggested that high-frequency words had stronger phonological representations (e.g., with higher activation levels). If the copying mechanism is better able to read and copy stronger representations, there will be a lower rate of phonological errors on high-frequency lexical items. Our data are thus compatible with several quite different models of language production, provided that lexical frequency is encoded in such a way as to affect lower levels of processing and is also encoded at least partially in terms of strength, as also argued by Miller and Ellis (in press).

Several researchers have suggested that frequency effects may result, to some extent, from structural differences between high- and low-frequency words (Landauer \& Streeter, 1973; Luce, 1985). High-frequency words tend to have larger similarity neighborhoods (i.e., be similar to more words) and to contain more intelligible phonemes. Since it is as yet unclear exactly how these structural differences can account for all known frequency effects, we cannot rule out the possibility that structural differences, rather than frequency per se, might be at the root of the results of Studies 1, 2, and 3. Structural differences cannot account for the results of Study 4, however, since there were no significant differences between the high- and low-frequency verb groups in (1) phoneme distributions, (2) the number of phonemes that were characteristic of high-versus low-frequency verbs in Landauer and Streeter's study, (3) the number of words that predominantly have phonemes characteristic of highrather than low-frequency words, or (4) the average similarity neigborhood size. The frequency effects in Study 4 are presumably due to word frequency rather than to structural factors, although this alternative cannot be ruled out for Studies 1, 2, and 3 at this time.

The results of this work have a number of ramifications for language learning. Butler Platt and MacWhinney (1983) presented evidence that children were able to store their own errors, for example, ated, as new lexical items. They suggested that children might also learn correct regularly inflected forms, such as jumped, in the same way. Over time, the former, incorrect, items are presumably eradicated from the lexicon, while the latter, correct, items may be retained into adulthood. The current study adds some plausibility to their suggestion.

The current study also raises new questions of a different sort for language learning. It has often been noted that certain small nonidiomatic phrases are very frequent and could potentially function as lexical items (MacWhinney, 1982). For example, Umeda and Kahn (1982) noted that of the is the 12th most frequent "word" in the Brown corpus (the texts on which the word-frequency count of Francis and Kučera [1982] is based). Are such common sequences also memorized and given their own lexical entries? Our results lend some plausibility to such storage, but further research is needed to decide the question.

It appears that there are two routes leading to regularly inflected forms in language production: (1) direct access of the separately stored form, and (2) application of an inflectional rule to the base form. Our data are compatible with several combinations of these two routes. Only further work can determine which combination is correct. (1) The lexical route is used for high-frequency forms, and the rule route is used for low-frequency forms. (2) Both routes can be used for all inflected forms. The 
speaker decides at the outset which route to use. The probability of using the lexical route increases as a function of lexical frequency. (3) Both routes are always used, in a horse race model. Whichever route goes to completion first is used. For high-frequency forms, the lexical route is faster and more likely to win. (4) Both routes are used in parallel and converge on the same two morphemes. The lexical route adds activation to the morphemes that are also activated by the rule route, speeding access and increasing accuracy. For these last three combinations, there are certainly some inflected forms that are not separately stored in the lexicon and for which the lexical route is consequently not used; for example, new forms and extremely rare forms. How frequent an inflected form must be before it is given a separate lexical entry is as yet unknown. It appears that the questions we have addressed in this study lead to further questions of a more finegrained nature.

\section{REFERENCES}

Atkinson, R. C., \& Shiffrin, R. M. (1968). Human memory: A proposed system and its control processes. In K. W. Spence \& J. T. Spence (Eds.), The psychology of learning and motivation (Vol. 2). New York: Academic Press.

Balota, D. A., \& Chumbley, J. I. (1985). The locus of word-frequency effects in the pronunciation task: Lexical access and/or production? Journal of Memory \& Language, 24, 89-106.

BERKo, J. (1958). The child's learning of English morphology. Word, 14, $150-177$

BRADLEY, D. (1980). Lexical representation of derivational relation In M. Aronoff \& M.-L. Kean (Eds.), Juncture. Cambridge, MA: MIT Press.

Brown, R., \& McNeILL, D. (1966). The "tip of the tongue" phenomenon. Journal of Verbal Learning \& Verbal Behavior, 5, 325-337.

Butler Platt, C., \& MacWhinNey, B. (1983). Error assimilation as a mechanism in language learning. Journal of Child Language, 10, 401-414.

BUtTERWORTH, B. (1979). Hesitations and the production of verbal paraphasias and neologisms in jargon aphasia. Brain \& Language, 8, 131-161.

BUTTERWORTH, B. (1983). Lexical representation. In B. Butterworth (Ed.), Language production: Vol. 2. Development, writing, and other language processes (pp. 257-294). London: Academic Press.

BYBEE, J., \& BREWER, M. (1981). Explanation in morphophonemics: Changes in Provencal and Spanish preterite forms. Lingua, 52. 201-242.

Bybee, J., \& SLobin, D. I. (1982). Rules and schemas in the development and use of the English past tense. Language. 58, 265-289.

Chomsky, N., \& Halle, M. (1968). The sound pattern of English. New York: Harper \& Row.

Cole, R. A., \& JAKIMIK, J. (1980). How are syllables used to recognize words? Journal of the Acoustical Society of America, 67. 965-970

Cutler, A. (1980). Errors of stress and intonation. In V. Fromkin (Ed.), Errors in linguistic performance: Slips of the tongue, ear, pen, and hand (pp. 67-80). New York: Academic Press.

Ebbinghaus, H. (19l3). Memory (H. A. Ruger \& C. E. Bussenius, Trans.). New York: Teachers' College. (Original work published 1885)

Ellis, A. W., Miller, D., \& Sin, G. (1983). Wernicke's aphasia and normal language processing: A case study in cognitive neuropsychology. Cognition, 15, 111-144

Estes, W. K. (1955). Toward a statistical theory of learning. Psychological Review, 57, 94-107.

FORSTER, K. I. (1976). Accessing the mental lexicon. In E. Walker \& R. Wales (Eds.), New approaches to language mechanisms. Amster- dam: North-Holland.

FranCIS, W. N., \& KuČERA, H. (1982). Frequency analysis of English usage: Lexicon and grammar. Boston: Houghton Mifflin.

GaRRETt, M. (1980). Levels of processing in sentence production. In B. Butterworth (Ed.), Language production: Vol. 1. Speech and talk (pp. 177-220). London: Academic Press.

GibSON, E. J., \& GUINET, L. (1971). Perceptions of inflections in brief visual presentations of words. Journal of Verbal Learning \& Verbal Behavior, 10, 182-189.

HALL, J. F. (1954). Learning as a function of word frequency. American Journal of Psychology, 67, 138-140.

HOOPER, J. B. (1976). Word frequency in lexical diffusion and the source of morpho-phonemic change. In W. Christie (Ed.), Current progress in historical linguistics (pp. 95-105). Amsterdam: North-Holland.

HowEs, D. (1964). Application of the word frequency concept to aphasia. In A. V. S. DeReuck \& M. O'Connor (Eds.), Disorders of language. London: Churchill.

Hunson, G. (1980). Automatic alternations in nontransformational phonology. Language, 56, 94-125.

JACKENDOFF, R. (1975). Morphological and semantic regularities in the lexicon. Language, 51, 639-671.

Kempley, S. T., \& MORTON, J. (1982). The effects of priming with regularly and irregularly related words in auditory word recognition. British Journal of Psychology, 73, 441-454.

Landauer, T. K., \& Streeter, L. A. (1973). Structural differences between common and rare words: Failure of equivalence assumptions for theories of word recognition. Journal of Verbal Learning \& Verbal Behavior, 12, 119-131

Leben, W., \& Robinson, O. W. (1977). Upside-down phonology. Langauge, $\mathbf{5 3}, 1-20$

LUCE, P. A. (1985). Structural distinctions between high and low frequency words in auditory word recognition. Unpublished doctoral dissertation. Indiana University.

Lukatela, G., Gligorijevic, B., Kostic, B., \& Turvey, M. T. (1980). Representation of inflected nouns in the internal lexicon. Memory $\&$ Cognition, 8, 415-423.

MACKAY, D. G. (1976). On the retrieval and lexical structure of verbs. Journal of Verbal Learning \& Verbal Behavior, 15, 169-182.

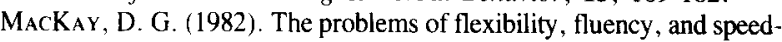
accuracy trade-off in skilled behavior. Psychological Review, 89, 483-506.

MaCWhinNeY, B. (1978). The acquisition of morphophonology. Monographs of the Society for Research in Child Development, 43(Whole No. 1).

MacWhinner, B. (1982). Basic syntactic processes. In S. Kuczaj II (Ed.), Language development: Vol. 1. Syntax and semantics (pp. 73136). Hillsdale, NJ: Erlbaum.

MCClelland, J. L., \& Rumelhart, D. E. (1981). An interactive activation model of context effects in letter perception: Part 1. An account of basic findings. Psychological Review, 88, 375-407.

Muller, D., \& Ellis, A. W. (in press). Language production in neologistic jargonaphasia and normal lexical activation for speech and writing. In M. Coltheart, R. Job, \& G. Sartori (Eds.), The cognitive neuropsychology of language. London: Erlbaum.

MORTON, J. (1969). The interaction of information in word recognition. Psychological Review, 76, 165-178.

Murrell, G. A., \& Morton, J. (1974). Word recognition and morpheme structure. Journal of Experimental Psychology. 102, 963-968

PAUL, H. (1886). Prinzipien der Sprachgeschichte. Halle: Newmeyer.

Peters, A. M. (1983). The units of language acquisition. Cambridge Cambridge University Press.

Shattuck-Hufnagel, S. (1979). Speech errors as evidence for a serial ordering mechanism in sentence production. In W. E. Cooper \& E. Walker (Eds.), Sentence processing (pp. 295-342). New York: Halsted Press.

SHiffrin, R. M., \& SCHNEIDER, W. (1977). Controlled and automatic human information processing: II. Perceptual learning, automatic attending, and a general theory. Psychological Review, 84, 127-190

Stanners, R. F., Nerser, J. J., Hernon, W. P., \& Hall, R. (1979). Memory representation for morphologically related words. Journal of Verbal Learning \& Verbal Behavior, 18, 399-413. 
Stemberger, J. P. (1984). Structural errors in normal and agrammatic speech. Cognitive Neuropsychology, 1, 281-313.

STEMBERGER, J. P. (1985a). Bound morpheme loss errors in normal and agrammatic speech: One mechanism or two? Brain \& Language. 25, 246-256.

Stemberger, J. P. (1985b). An interactive activation model of language production. In A. Ellis (Ed.), Progress in the psychology of language (Vol. 1, pp, 143-186). London: Erlbaum.

Stemberger, J. P., \& MacWhinney, B. (in press). Form-oriented inflectional errors in language processing. Cognitive Psychology.

TAFT, M. (1981). Prefix stripping revisited. Journal of Verbal Learning \& Verbal Behavior, 20, 289-297.

TAFT, M. (1984). Evidence for an abstract lexical representation of word structure. Memory \& Cognition, 12, 264-269.

TAFT, M., \& FORSTER, K. (1975). Lexical storage and retrieval of prefixed words. Journal of Verbal Learning \& Verbal Behavior, 14, 638-647.
ThORNDIKE, E. L. (1898). Animal intelligence: An experimental study of the associative processes in animals. Psychological Review, 2(Monograph Suppl. 8).

UMEDA, N., \& KAHN, D. (1982). Frequency of occurrence of two- and three-word sequences in English. Journal of the Acoustical Society of America, 72, 2031-2033.

VENNEMANN, T. (1974). Words and syllables in natural generative phonology. In The parassession on natural phonology (pp. 346-374). Chicago: Chicago Linguistic Society.

WALSh, T., \& PARKer, F. (1983). The duration of morphemic and nonmorphemic /s/ in English. Journal of Phonetics, 11, 201-206.

(Manuscript received January 23, 1985; revision accepted for publication June 10, 1985.) 